\title{
Resazurin Microplate Assay: Rapid Assay for Detection of Methicillin Resistant Staphylococcus aureus
}

\author{
Hala Mahmoud Hafez ${ }^{1}$, Dalia H Abd El Hamid ${ }^{1}$, Dina Tarek ${ }^{1}$ and \\ Fatma Al-Zahraa M. Gomaa ${ }^{2}$
}

\author{
${ }^{1}$ Department of Clinical Pathology, Faculty of Medicine, Ain Shams University, Egypt \\ ${ }^{2}$ Department of Microbiology, Faculty of Pharmacy, Al-Azhar University for Girls, Egypt \\ *Corresponding author
}

\begin{abstract}
A B S T R A C T
Keywords

MRSA, Resazurin, REMA, mecA gene, Cefoxitin.

Article Info

Accepted:

02 March 2017

Available Online:

10 April 2017

The increasing methicillin resistant Staphylococcus aureus (MRSA) infections pose a serious threat. Accurate and rapid detection of methicillin resistance is important for ensuring the prompt start of antibiotherapy and control of MRSA in the hospitals. Molecular detection of mecA gene is the gold standard for identification of MRSA isolates. However, many laboratories don't have the capacity for molecular techniques. Resazurin is a dye used as an oxidation reduction indicator in bacterial cell viability assays. The aim of the study was to introduce resazurin microplate assay (REMA) as a new colorimetric method for identification of MRSA. The study included 100 Staph. aureus clinical isolates which were tested for their susceptibility to methicillin by the cefoxitin (30ug) disc diffusion (DD) method and REMA. Detection of the mecA gene was done by PCR. Out of the 100 studied isolates, 65\% were MRSA by DD and the REMA. A highly significant association was found between the results of DD method and the results of REMA. The $m e c A$ gene was detected in $64 / 65$ of the MRSA isolates. There was a highly significant association between the results of REMA and that of the PCR for the mecA gene. It is concluded that the REMA is a sensitive and specific assay for rapid phenotypic detection of MRSA in poor resource laboratories.
\end{abstract}

\section{Introduction}

Methicillin-resistant Staphylococcus (Staph.) aureus (MRSA) is considered one of the most virulent pathogens in hospitals and intensive care units (ICU) worldwide (Pape et al., 2006). MRSA was found to be the most common pathogen identified in the United States hospitals (Stoakes et al., 2006) and accounts for $63 \%$ of nosocomial infections in Egypt (Borg et al., 2007). Moreover, new strains of MRSA associated with aggressive infections in young, otherwise healthy patients have emerged in the community (Stoakes et al., 2006).
Several studies have demonstrated that the MRSA infected patients tend to have longer hospital and ICU stays, higher rates of ventilator use, greater risks of death, and more adverse clinical outcomes (such as renal failure and hemodynamic instability) as compared to those patients infected with methicillin sensitive Staph. aureus (MSSA) (Cosgrove et al., 2005).

Moreover, Abramson and Sexton (2000) calculated an excess attributable cost of $\$ 27,083$ for MRSA bloodstream infection versus \$9,661 for MSSA bloodstream 
infection. The authors reported that the excess costs were not only due to the prolonged hospitalization and increase morbidity and mortality, but also due to the expensive drugs used for treatment such as vancomycin, rifampicin, fusidic acid and quinolones.

The early detection of MRSA allows for the early initiation of the appropriate antibiotic therapy which, in turn, reduces mortality, the length of hospitalization, and costs associated with MRSA infections (Grobner et al., 2009).

A wide range of methods have evolved for the identification of MRSA in the clinical laboratories such as dilution methods (agar dilution or broth microdilution), agar screening method, E-test method and disc diffusion method. In addition, the chromogenic agar medium and the latex agglutination test, used for the detection of the penicillin-binding protein $2 \mathrm{a}$ ( $\mathrm{PBP} 2 \mathrm{a})$, have been used for the screening of nasal carriers. Yet, all these methods are culturebased methods that require 24-48 hours incubation (Brown et al., 2005).

Molecular techniques for the detection of $m e c A$ gene are viewed as the "gold standard" for determining MRSA. Polymerase chain reaction (PCR) for amplification of the mecA gene can be performed within few hours, providing same day results. However, these methods have certain disadvantages, including the need to batch clinical specimens, greater technical demands than culture, expensive reagents and the need for specialized laboratory equipment. Moreover, for better sensitivity specimens are precultured on broth media, thus limiting the rapid detection advantage of the molecular methods (Sturen Berg, 2009).

Resazurin is used as an oxidation reduction indicator in bacterial cell viability assays. It is also used for determination of contamination and antimicrobial activity in addition to its use in cell viability assays (Palomino et al., 2002). In 2006, Coban and colleagues used the resazurin microplate assay (REMA) for testing oxacillin- and vancomycin-resistant Staph. aureus isolates, and reported consistent results in comparison with the results using the liquid microdilution method. Moreover, Coban (2012) investigated the efficacy of the REMA to detect MRSA isolated from clinical samples.

The author demonstrated that the results of the REMA were concordant with the results of molecular methods for the detection of MRSA. Since the REMA is easy to perform and can save time in the determination of MRSA, it provides an option to clinical microbiology laboratories with limited facilities to detect MRSA earlier.

The aim of this work was to introduce the resazurin microplate assay (REMA) as a new colorimetric method for the identification of MRSA and to investigate its effectiveness as a rapid, sensitive and specific test for the detection of methicillin resistance among Staph. aureus clinical isolates.

\section{Materials and Methods}

The study was carried out at the Microbiology Laboratory, Clinical pathology Department, Ain Shams University Hospital.

A total number of 100 Staph. aureus isolates was collected from different clinical samples submitted to the laboratory for routine culture and susceptibility testing. The isolates were sub-cultured onto a plate of blood agar supplemented with $7 \%$ human blood to obtain fresh and separate colonies. After overnight incubation at $36 \pm 1^{\circ} \mathrm{C}$ under aerobic conditions, growing isolates were subjected to: 
Detection of methicillin resistance by the disk diffusion method, using the cefoxitin (30ug) disc

Following the recommendations of the Clinical Laboratory Standard Institute (CLSI), isolates with zone diameters $\leq 21 \mathrm{~mm}$ were considered cefoxitin resistant (CLSI, 2014).

\section{Resazurin microplate assay (REMA)}

The test was done in microtitre plates as described by Coban (2012) using the broth microdilution method defined by the CLSI.

$50 \mu 1$ of double strength Muller-Hinton broth was distributed from the 1 st to the 12th well in each raw.

$50 \mu \mathrm{l}$ of cefoxitin solution $(64 \mu \mathrm{l} / \mathrm{ml})$ was pipetted into the 1st test wells of each microtiter line and mixed well with the broth.

Then, $50 \mu \mathrm{l}$ of the cefoxitin-broth mixture were transferred from the 1st well to the 2nd well in the next raw and so on till the 7 th well and the last $50 \mu \mathrm{l}$ of the antibiotic broth mixture were discarded. The 8th well in each line was left as a control well (antibiotic-free control well).

Five microliters of a bacterial suspension, adjusted to a 0.5 MacFarland turbidity standard, was inoculated into each antibiotic-containing and control (antibiotic-free) well.

Plates were wrapped loosely with a cling film to avoid suspension dehydration and incubated at $35^{\circ} \mathrm{C}$, under aerobic conditions, for five hours.

At the end of the incubation period, $15 \mu$ of $0.02 \%$ resazurin were added into all wells and plates were re-incubated for additional one hour.

When a color change from blue to red was seen in the antibiotic free control wells (8th well in each line), the MIC values for cefoxitin were determined. The MIC is considered the last well in which there is no color change (Figures 1 and 2).

Detection of the mecA gene by real time polymerase chain reaction

Bacterial DNA was extracted using Bacteria DNA Preparation Kit (Thermo Scientific, EU Lithuania) according to manufacturer's instructions. DNA amplification was done using Maxima SYBR Green qPCR Master Mix (2X) (Thermo Scientific, EU Lithuania). Primers used in the amplification were designed according to (Rallapalli et al., 2008). A reaction master mix was prepared by adding the components described in table 1 for each $25 \mu \mathrm{l}$ reaction in a tube at room temperature. MRSA strain (ATCC 43300) was used as positive control whereas sterile distilled water was used as negative control.

Reaction tubes were then loaded onto the Stratagene Mx3000P (Stratagene Mx3000P QPCR Systems, La Jolla, CA 92037, USA) and the amplification program was adjusted as follows: initial denaturation at $95^{\circ} \mathrm{C}$ for 10 minutes, followed by 40 cycles of amplification consisting of denaturation at $95^{\circ} \mathrm{C}$ for 15 seconds, annealing at $60^{\circ} \mathrm{C}$ for 30 sec, and extension at $72^{\circ} \mathrm{C}$ for $30 \mathrm{sec}$. The amplification program was followed immediately by a melt program consisting of 1 minute at $95^{\circ} \mathrm{C}, 30 \mathrm{sec}$ at $55^{\circ} \mathrm{C}$ then again to $95^{\circ} \mathrm{C}$ for $30 \mathrm{sec}$.

\section{Statistical analysis}

Data were analyzed using the IBM SPSS statistics (V. 22.0, IBM Corp., USA, 2013).

Categorical data were expressed as both number and percentage

The Chi-square test $\left(\mathrm{X}^{2}\right.$ value) was done to determine the association between results of different tests. 
The diagnostic performance of the cefoxitin (30ug) disc diffusion method and the resazurin microplate assay was expressed by: The diagnostic sensitivity, the diagnostic specificity, the positive predictive value and the negative predictive value.

\section{Results and Discussion}

1. Comparison between the results of the REMA and the results of the cefoxitin (30ug) disc diffusion method

The results of the resazurin microplate assay showed that $3 \%$ of the isolates had cefoxitin MIC $1 \mathrm{ug} / \mathrm{ml}, 32 \%$ had cefoxitin MIC $2 \mathrm{ug} / \mathrm{ml}$, $31 \%$ had cefoxitin MIC 8ug/ml, 12\% had cefoxitin MIC 16ug/ml, 4\% had cefoxitin MIC $32 \mathrm{ug} / \mathrm{ml}$, and $18 \%$ had cefoxitin MIC $>32 \mathrm{ug} / \mathrm{ml}$. Accordingly, 35 out of the 100 studied Staph. aureus isolates (35\%) were determined to be susceptible to methicillin or MSSA (cefoxitin MIC <8ug/ml) whereas $65 \%$ were MRSA (cefoxitin MIC $\geq 8 \mathrm{ug} / \mathrm{ml}$ ). The same results were obtained by the cefoxitin (30ug) disc diffusion method.

There was a highly significant association between the results of the cefoxitin (30ug) disc diffusion method and the results of the REMA $(\mathrm{P}<0.01)$ (Table 2). The finding of this study is in accordance with the results of Baker and Tenover (1996) who reported $100 \%$ agreement between the resazurin microplate assay and the broth microdilution method for the detection of oxacillin resistance in Staph. aureus. Moreover, Coban (2012) reported $100 \%$ agreement between the resazurin microplate assay for the rapid determination of MRSA and the cefoxitin MIC determined by the reference broth microdilution method.

Comparison between the results of the REMA and the Results of the mecA gene detection by PCR

Out of the 65 Staph. aureus isolates, that were determined to be MRSA by both the cefoxitin (30ug) disc diffusion method and the REMA, we were able to detect the mecA gene in only 64 isolates. None of the isolates determined to be MSSA by the cefoxitin (30ug) disc diffusion method and the REMA had the mecA gene. There was a significant association between the results of the REMA and the results of the mecA gene $(P<0.01)$ (Table 3).

Table.1 Components of reaction mixture for each 25 ul reaction

\begin{tabular}{|c|c|c|}
\hline Reaction component & Concentration & Volume \\
\hline $\begin{array}{c}\text { Maxima® SYBR Green qPCR } \\
\text { Master Mix (2X), no ROX }\end{array}$ & $12.5 \mathrm{ul}$ & $12.5 \mu \mathrm{l}$ \\
\hline $\begin{array}{c}\text { Forward Primer } \\
\text { AAA ATC GAT GGT AAA GGT } \\
\text { TGG C }\end{array}$ & $0.3 \mu \mathrm{M}$ & $0.75 \mu \mathrm{l}(1: 10)$ \\
\hline $\begin{array}{c}\text { Reverse Primer } \\
\text { ATG TCT GCA GTA CCG GAT } \\
\text { TTG C }\end{array}$ & $0.3 \mu \mathrm{M}$ & $0.75 \mu \mathrm{l}(1: 10)$ \\
\hline ROX Solution & $10 \mathrm{nM} / 100 \mathrm{nM}$ & $0.05 \mu \mathrm{l}(1: 10)$ \\
\hline Template DNA & $\leq 500 \mathrm{ng}$ & $5 \mu \mathrm{l}(1: 10)$ \\
\hline Water, nuclease-free & to $25 \mathrm{ul}$ & $6 \mu \mathrm{l}$ \\
\hline Total reaction volume & $25 \mathrm{ul}$ & $25 \mu \mathrm{l}$ \\
\hline
\end{tabular}


Table.2 Association between the results of cefoxitin disc diffusion method and the results of resazurin microplate assay

\begin{tabular}{|c|c|c|c|c|c|c|c|}
\hline & \multicolumn{2}{|c|}{$\overline{D D}$} & \multirow{2}{*}{ Total } & \multirow{2}{*}{$X^{2}$ value } & \multirow{2}{*}{$\mathbf{P}$} \\
\hline & & & Neg & Pos & & & \\
\hline \multirow{4}{*}{$\begin{array}{c}\text { Resazurin } \\
\text { microplate } \\
\text { assay }\end{array}$} & \multirow{2}{*}{ Neg } & Count & 35 & 0 & 35 & \multirow{6}{*}{100.00} & \multirow{6}{*}{$\begin{array}{c}0.00 \\
(\mathrm{HS})^{*}\end{array}$} \\
\hline & & $\%$ & $100.0 \%$ & $0.0 \%$ & $35.0 \%$ & & \\
\hline & \multirow{2}{*}{ Pos } & Count & 0 & 65 & 65 & & \\
\hline & & $\%$ & $0.0 \%$ & $100.0 \%$ & $65.0 \%$ & & \\
\hline \multirow{2}{*}{\multicolumn{2}{|c|}{ Total }} & Count & 35 & 65 & 100 & & \\
\hline & & $\%$ & $100.0 \%$ & $100.0 \%$ & $100.0 \%$ & & \\
\hline
\end{tabular}

*HS = highly significant

Table.3 Association between the results of resazurin microplate assay and the results of PCR

\begin{tabular}{|c|c|c|c|c|c|c|c|}
\hline & \multicolumn{2}{|c|}{ PCR } & \multirow{2}{*}{ Total } & \multirow{2}{*}{$X^{2}$ value } & \multirow{2}{*}{$\mathbf{P}$} \\
\hline & & & Neg & Pos & & & \\
\hline \multirow{4}{*}{$\begin{array}{l}\text { Resazurine } \\
\text { microplate } \\
\text { assay }\end{array}$} & No & Count & 35 & 0 & 35 & \multirow{6}{*}{95.726} & \multirow{6}{*}{$\begin{array}{c}0.00 \\
(\mathrm{HS})\end{array}$} \\
\hline & Neg & $\%$ & $97.2 \%$ & $0.0 \%$ & $35.0 \%$ & & \\
\hline & Pos & Count & 1 & 64 & 65 & & \\
\hline & $10 \mathrm{~s}$ & $\%$ & $2.8 \%$ & $100.0 \%$ & $65.0 \%$ & & \\
\hline \multirow{2}{*}{\multicolumn{2}{|c|}{ Total }} & Count & 36 & 64 & 100 & & \\
\hline & & $\%$ & $100.0 \%$ & $100.0 \%$ & $100.0 \%$ & & \\
\hline
\end{tabular}

*HS = highly significant

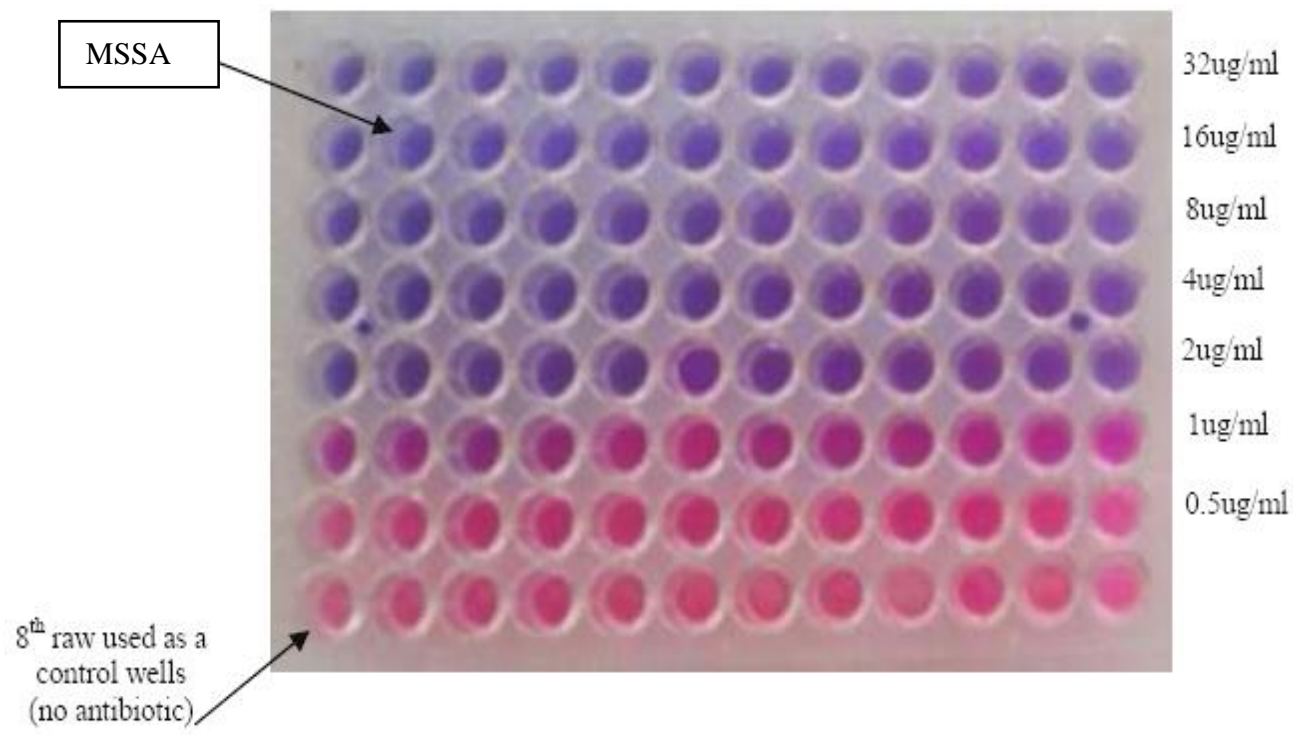

Figure.1 Resazurin microplate assay showing methicillin susceptible Staph. aureus (MSSA): the 12 isolates were tested in the plate arranged from the left to the right and the concentration of antibiotic ranged from $32-0.5 \mathrm{ug} / \mathrm{ml}$ arranged from $1^{\text {st }}$ to $7^{\text {th }}$ raw. Last $8^{\text {th }}$ raw used as a control (antibiotic free well). In this picture the MIC for all the 12 isolates was $2 \mathrm{ug} / \mathrm{ml}$ 


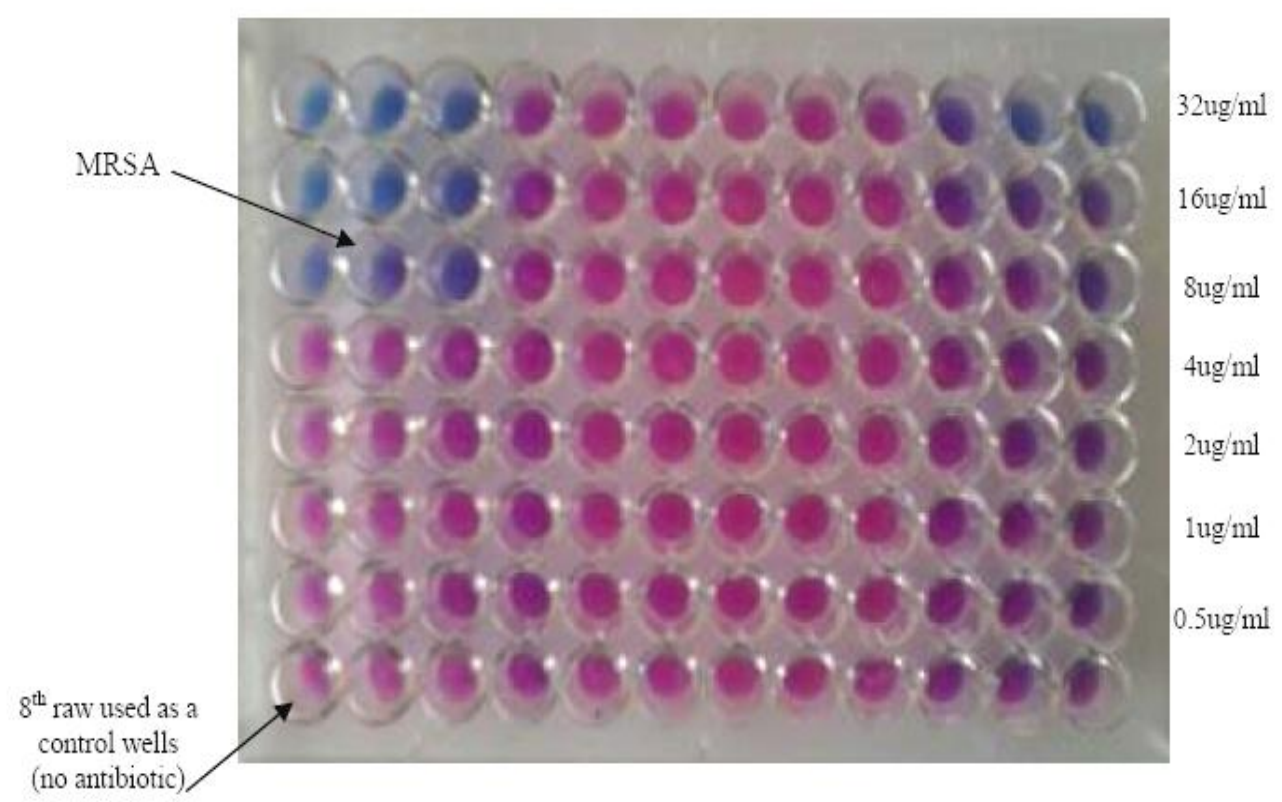

Figure.2 Resazurin microplate assay showing Methicillin Resistant Staph. aureus (MRSA): the 12 isolates were tested in the plate arranged from the left to the right and the concentration of antibiotic ranged from $32-0.5 \mathrm{ug} / \mathrm{ml}$ arranged from $1^{\text {st }}$ to $7^{\text {th }}$ raw. Last $8^{\text {th }}$ raw used as a control (antibiotic free well). In this picture the MIC for all the 12 isolates was as follow: $1^{\text {st }}, 2^{\text {nd }}, 3^{\text {rd }}$, was $8 \mathrm{ug} / \mathrm{ml} ; 4^{\text {th }}, 5^{\text {th }}, 6^{\text {th }}, 7^{\text {th }}, 8^{\text {th }}, 9^{\text {th }}$ was $>32 \mathrm{ug} / \mathrm{ml} ; 10^{\text {th }}, 11^{\text {th }}, 12^{\text {th }}$ was $32 \mathrm{ug} / \mathrm{ml}$

The present study results are in agreement with the results obtained by Coban (2012) who evaluated the effectiveness of the resazurin microplate assay for the rapid determination of methicillin resistance among Staph. aureus isolates compared with the result of $m e c A$ gene detection by PCR. The authors found that the resazurin microplate assay has sensitivity and specificity of $100 \%$, respectively.

In the current study, only one isolate was determined to be resistant to the cefoxitin by the cefoxitin (30ug) disc diffusion method (zone diameter $>21 \mathrm{~mm}$ ) and was found to be negative for the mecA gene by the PCR. The same isolate had a cefoxitin MIC value of $>32 \mathrm{ug} / \mathrm{ml}$ when it was tested by the resazurin microplate assay. A similar finding was reported by Garcia-Álvarez and colleagues (2011) who noted that some Staph. aureus strains resistant to methicillin but negative for the mecA gene have been discovered in humans. This novel divergent mecA gene was designated mecA $A_{\mathrm{LGA} 25 \mathrm{~L}}$ and was $70 \%$ homogenous to Staph. aureus mecA gene. Although routine culture and antimicrobial susceptibility testing can identify Staph. aureus isolates encoding $m e c A_{\mathrm{LGA} 25 \mathrm{~L}}$ gene as methicillin resistant, this discovery highlights new problems in MRSA detection if currently available confirmatory tests like PCR and PBP2a latex agglutination tests are used (Monecke et al., 2011).

\section{Performance characteristics of the REMA}

Compared to the results of RT-PCR for the $m e c A$ gene, the sensitivity of the resazurin microplate assay for the detection of $m e c A$ positive MRSA was $100 \%$, the specificity was $97.2 \%$. The assay was found to have a positive predictive value of $98.5 \%$ and $100 \%$ negative predictive value. The resazurin microplate assay had the same diagnostic performance as the cefoxitin disc diffusion method. 
This study concluded that the resazurin microplate assay is a sensitive and specific assay that can be used for the rapid detection of methicillin susceptibility among clinical isolates of Staph. aureus. The results of the resazurin microplate assay have $100 \%$ agreement with that of the cefoxitin (30ug) disc diffusion method. Yet, the resazurin microplate assay gives rapid results (within 6 hours) compared to the disc diffusion test which requires 24 hour incubation. In addition, the microplate format provides quantitative (MIC) results. Furthermore, it has the advantage over PCR in being able to detect novel Staph. aureus strains with divergent mecA gene.

\section{Recommendations}

The use of the resazurin microplate assay as a reliable, simple, rapid and cost-effective assay for the detection of MRSA particularly in poor resource laboratories.

Further studies investigating the value of the resazurin microplate assay in the detection of other drug-resistant organisms e.g., vancomycin-resistant Enterococci and multidrug resistant Mycobacteria.

\section{References}

Abramson, M.A. and Sexton, D.J. 2000. Nosocomial methicillin-resistant and methicillin-susceptible Staphylococcus aureus primary bacteremia: at what costs? Infect. Control Hosp. Epidemiol., 20: 408-11.

Baker, C.N. and Tenover, F.C. 1996. Evaluation of alamar colorimetric broth microdilution susceptibility testing method for Staphylococci and Enterococci. J. Clin. Microbiol., 34: 2654-59.

Borg, M.A., De Kraker, M., Scicluna, E., van de Sande-Bruinsma, N., Tiemersma, E.,
Monen, J., Grundmann, H. 2007. Prevalence of methicillin resistant Staphylococcus aureus (MRSA) in invasive isolates from southern and eastern Mediterranean countries. $J$. Antimicrob. Chemother., 60: 1310-15.

Brown, D.F.J., Edwards, D.I., Hawkey, P.M., Morrison, D., Ridgway, G.L., Towner, K.J. and Wren, M.W.D. 2005. On behalf of the Joint Working Party of the British Society for Antimicrobial Chemotherapy, Hospital Infection Society and Infection Control Nurses Association (2005): Guidelines for the laboratory diagnosis and susceptibility testing of methicillin-resistant Staphylococcus aureus (MRSA). J. Antimicrob. Chemother., 56: 1000-18.

Clinical and Laboratory Standards Institute (CLSI). 2014. Performance Standards for Antimicrobial Susceptibility Testing; Twenty-Fourtht Informational Supplement. CLSI document M100-S21 (ISBN 1-56238-742-1). Clinical and Laboratory Standards Institute, 940 West Valley Road, Suite 1400, Wayne, Pennsylvania 19087 USA.

Coban, A.Y. 2012. Rapid determination of methicillin- resistant clinical isolates among the Staphylococcus aureus by colorimetric methods. J. Clin. Microbiol., 50: 2191-93.

Coban, A.Y., Bozdogan, B., Cihan, C.C., Cetinkaya, E., Bilgin, K., Darka, O., Akgunes, A., Durupinar, B., Appelbaum, P.C. 2006. Two new colorimeteric methods for early detection of vancomycin and oxacillin resistance in Staphylococcus aureus. J. Clin. Microbiol., 44: 580- 82.

Cosgrove, S.E., Qi, Y., Kaye, K.S., Harbarth, S., Karchmer, A.W., Carmeli, Y. 2005. The impact of methicillin resistance in Staphylococcus aureus bacteraemia on patient outcomes: mortality, length of stay, and hospital charges. Infect. 
Control Hosp. Epidemiol., 26: 166-74. García-Álvarez, L., Holden, M.T., Lindsay, H., Webb, C.R., Brown, D.F., Curran, M.D., Walpole, E., Brooks, K., Pickard, D.J., Teale, C., Parkhill, J., Bentley, S.D., Edwards, G.F., Girvan, E.K., Kearns, A.M., Pichon, B., Hill, R.L., Larsen, A.R., Skov, R.L., Peacock, S.J., Maskell, D.J., Holmes, M.A. 2011. Meticillin-resistant Staphylococcus aureus with a novel mecA homologue in human and bovine populations in the UK and Denmark: a descriptive study. Lancet Infect. Dis., 11: 595-603.

Grobner, S., Dion, M., Plante, M., Kempf, V.A. 2009. Evaluation of the BD GeneOhm StaphSR Assay for the detection of methicillin-resistant and methicillin susceptible Staphylococcus aureus isolates from spiked positive blood culture bottles. J. Clin. Microbiol., 47: 1689-94.

Monecke, S., Coombs, G., Shore, A.C., Coleman, D.C., Akpaka, P., Borg, M., Chow, H., Ip, M., Jatzwauk, L., Jonas, D., Kadlec, K., Kearns, A., Laurent, F., O'Brien, F.G., Pearson, J., Ruppelt, A., Schwarz, S., Scicluna, E., Slickers, P., Tan, H.L., Weber, S., Ehricht, R. 2011. A field guide to pandemic, epidemic and sporadic clones of methicillinresistant Staphylococcus aureus. PLoS One; 6: e17936.

Palomino, J.C., Martin, A., Camacho, M., Guerra, H., Swings, J., Portaels, F.
2002. Resazurin microtiter assay plate, simple and inexpensive method for detection of drug resistance in Mycobacterium tuberculosis. Antimicrob. Agents Chemother., 46: 2720-23.

Pape, J., Waldin, J. and Nachamkin, I. 2006. Use of BBL Chromagar MRSA medium for identification of methicillin-resistant Statphylococcus aureus directly from blood cultures. J. Clin. Microbiol., 44(7): 2575-76.

Rallapalli, S., Verghese, S. and Verma, R.S. 2008. Validation of multiplex PCR strategy for simultaneous detection and identification of methicillin resistant Staphylococcus aureus. Ind. J. Med. Microbial., 26(4): 361-64

Stoakes, L., Reyes, R., Daniel, J., Lennox, G., John, M.A., Lannigan, R., Hussain, Z. 2006. Prospective comparison of a new chromogenic medium, MRSA Select, to CHROMagar MRSA and mannitol-salt medium supplemented with oxacillin or cefoxitin for detection of methicillinresistant Staphylococcus aureus. J. Clin. Microbiol., 44: 637-39.

Sturenberg, E. 2009. Rapid detection of methicillin- resistant Staphylococcus aureus directly from clinical samples: methods, effectiveness and cost considerations. Ger. Med. Sci., 7: Doc06.

\section{How to cite this article:}

Hala Mahmoud Hafez, Dalia H Abd El Hamid, Dina Tarek and Fatma Al-Zahraa M Gomaa. 2017. Resazurin Microplate Assay: Rapid Assay for Detection of Methicillin Resistant Staphylococcus aureus. Int.J.Curr.Microbiol.App.Sci. 6(4): 174-181. doi: https://doi.org/10.20546/ijcmas.2017.604.020 